\title{
Analysis of the modern entrepreneurship education under the background of Internet economy
}

\author{
Wei Wang ${ }^{1}$, Ying Liu ${ }^{2}$ \\ ${ }^{1}$ Wenzhou Business College School of Information Engineering Wenzhou City China \\ 2Zhejiang Oriental Vocational Technical College Wenzhou City China
}

\begin{abstract}
Keywords: Internet economy, background, modern entrepreneurship, education development, trend analysis.
\end{abstract}

\begin{abstract}
In higher education, entrepreneurship education is actually the perfect embodiment of cultivating college students' innovative consciousness and entrepreneurial spirit. To analyze the integration of Ideological and political education and entrepreneurship education in colleges and universities, and to analyze the ideological and political education in colleges and universities, which provides a prerequisite for college students to start their own businesses and in the period of rapid development of socialism and the background of socialist market economy, it has become an inevitable trend to develop entrepreneurship in colleges and universities. Especially now in university entrepreneurship education for students is facing a major challenge, so we should cultivate college students itself in the aspects of quality, the correct analysis of Ideological and political education and entrepreneurship education in colleges and universities the fusion status, there is a clear direction, have a correct understanding. The current ideological and political education is an important part of the overall promotion of quality education in colleges and universities, but also in order to better their own ability to deal with all aspects of entrepreneurship. And we know that college students sometimes do not need to have a high culture, but if you have a lot of culture, then it will certainly help you succeed. So for now, the ideological and political education and entrepreneurship education fusion status is there is some misunderstanding, I hope you can know and understand many aspects, fusion and other aspects of Ideological and political education and entrepreneurship education in colleges and universities to better understand the problem.
\end{abstract}

\section{Introduction}

With the further deepening of economic system reform of our country and the international economic downturn, the contradiction between the number of job occupation and social development of the scale of colleges and universities in the popularization of higher education under the trend of the increasingly prominent. The rapid growth of college graduates and their single structure cannot match each other's social positions. The plight of college students' employment has raised new requirements for the training of application-oriented talents in colleges and universities. At present, the development of entrepreneurship education in China has made some achievements, but compared to foreign universities, it is still in its infancy.

In colleges and universities, the integration of ideological and political education and entrepreneurship education is essential. On the one hand, ideological and political education in colleges and universities will make the ideological and moral cultivation of students become excellent, personal connotation and self-cultivation become better, and will make everyone in the future social life in the performance of the more outstanding. But for the ideological and political education in colleges and universities, the most important thing is to change a person's mentality, it can be more conducive to personal development. Especially in the integration of Ideological and political education and entrepreneurship education, it is also a very important performance. For entrepreneurship education, we have to have a good attitude to it. In clleges and universities, the teacher is an important role for students in the future of entrepreneurship also plays a big role.

Entrepreneurship is not equal to employment, while entrepreneurship is not equal to the establishment of enterprises. If you want a new beginning, you must first give up some mistakes of 
the past. Although there are many loopholes and misunderstandings in the integration of Ideological and political education and entrepreneurship education in colleges and universities, we must go forward courageously and overcome difficulties. Therefore, itself is a combination of the own experience and extensive investigation found that fusion status of Ideological and political education and entrepreneurship education in colleges and universities, there exist a lot of problems, is the student cognition for the mistakes, the teacher ignored, in this regard the ideological and political education is not perfect and so on. Combined with their own work experience, on the basis of various investigations, this paper analyzes and probes into the integration of ideological and political education and entrepreneurship education in Colleges and universities, and gives specific solutions.

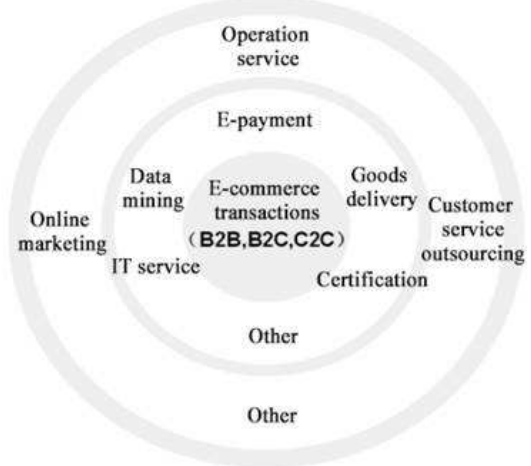

Figure.1 Internet economy

\section{The Proposed Methodology}

\subsection{Entrepreneurship Education.}

Entrepreneurship is the source of vitality for economic development. To start a great role in the economic development and social progress of countries and regions, has become the driving force of the high-speed development of economy, people have realized the significance of entrepreneurship for economic development and social progress of countries and regions. Entrepreneurial economy is an economic form based on innovation and new ventures, which was put forward by Drucker in 1985. Twenty-first Century is the era of great development of entrepreneurial economy, and the competition between countries is concentrated on the level of innovation and entrepreneurship. As the bridge of science and technology to the real productive forces, entrepreneurial activities have become the engine of economic development and an increasingly important driving force. Therefore, encouraging entrepreneurship has become the policy orientation of many countries, including china. As entrepreneur Larry Farrel said: "developing an entrepreneurial economy is the key to winning the global economic war in twenty-first Century.". The entrepreneurial economy has the remarkable function of enhancing the ability of independent innovation, changing the mode of economic growth and expanding social employment, thus attracting worldwide attention from the political, academic and industrial circles.

\subsection{Status of Vehicle Identification System.}

At present, the vehicle management part of the University by artificial identification: namely the school to the unit vehicle identification card issuing paper, by identification of whether the vehicle belongs to the entry guard units, foreign vehicles to the designated locations for temporary access procedures. This method is not only inefficient, inspection delays long, but also because it did not use technical means of anti-counterfeiting, forgery identification card buried a hidden danger.

Another part of the University adopts an inductive IC card access management system. Although this card is safe, confidential, difficult to counterfeit, easy to carry, durable and so on, but the traditional IC card itself is a short distance induction card, reading distance is only a few centimeters. In actual use, the owner needs to stop the vehicle, roll down the window, hold the IC card out of the window, swipe the card, and then continue to enter and out. The vehicle management system compared with a cost management system, during the inspection time longer, and did not bring convenience to the owners, especially in the rain and snow weather, hot weather and climate makes 
the owners more inconvenience. IC card entry and exit management system essentially needs parking, and cannot realize more advanced and humanized barrier free automatic access.

\subsection{Setting Up the Curriculum of Entrepreneurship Education.}

At present, the actual situation of China's entrepreneurship education, entrepreneurship education to MBA students, many colleges and universities provide entrepreneurship education courses in the form of elective courses, which exposed the shortcomings of university entrepreneurship education in the concept of. Moreover, even for undergraduate students to open entrepreneurship education courses in colleges and universities, the teaching object will be limited to such professional management, such as business management, resulting in the popularity of entrepreneurship courses is not high. According to the current situation of entrepreneurship curriculum setting in colleges and universities in China, entrepreneurship education curriculum can be divided into the following categories: one is the enterprise special theory course; the two is training for business plan competition; three is the entrepreneurship education related lectures; four is the practice of entrepreneurship education.

In the process of promoting entrepreneurship education, colleges and universities are restricted by various factors, such as time, funds and so on, and the related entrepreneurs have come from the teachers of business administration major. This kind of familiar business teachers despite the related theory, but many people especially the young teachers are lack of practical experience, no person in the enterprise actual work, only for entrepreneurs in simple business knowledge. Moreover, even if there are experienced mentors, but also because of the insufficient attention to the entrepreneurship education, lack of incentive mechanism for business mentor, tutor can make some dedicated in guiding the process, affected the implementation of entrepreneurship education.

In recent years, various types of entrepreneurial competitions have emerged, which have played an active role in college entrepreneurship education. On the one hand, can promote the enterprise competition to further strengthen the cultivation of students' innovative consciousness and abilities; on the other hand, the business competition can arouse students' entrepreneurial awareness to a great extent, to promote an important role in entrepreneurship education. But at the same time, universities should realize that entrepreneurship competition is only a competition, and its participation is very narrow, only a limited number of students, the knowledge learned through competition is not systematic. Entrepreneurial competition is just a kind of external guidance and form of entrepreneurship education. Distinguishing the relationship between competition and education is the key issue to further promote entrepreneurship education in colleges and universities. From the specific form of entrepreneurship practice in colleges and universities, most of the project planning model, such as participation in entrepreneurial design activities, the implementation of scientific and technological innovation program, the establishment of student entrepreneurship park and other forms.

\subsection{The Impact of the Internet Economy.}

Since the reform and opening up, China economic development a high degree of dependence on foreign, in 2008 China's external dependence is 72\%, every 100 yuan GDP have 72 yuan in foreign trade creation, while the same period of the United States foreign dependency is $24 \%$, which shows that the United States most of the domestic products in the domestic sales. In 2015, China's dependence on foreign is $56 \%$, the reasons for the decline is not their rise in consumer demand but a lack of demand for foreign trade, this is highly dependent on the international market to boost China's domestic market, it is very difficult for us to grasp the initiative to participate in the international division of labor and competition, once the international market demand, will cause serious influence to our country the foreign trade and economic.

Influenced by such factors as development stage, development concept, local GDP doctrine and institutional mechanism, China has entered an economic cycle of excess capacity. Some analysts said that overcapacity has become China's economic "nuclear threat", China's iron and steel, cement, electrolytic aluminum, flat glass, shipbuilding, photovoltaic and other industries, there is a serious excess capacity. Overcapacity causes losses in the industry, unemployment of enterprise workers, the increase in non-performing assets of banks, the bottleneck of energy resources and the deterioration 
of the ecological environment. This has a direct bearing on the improvement of people's livelihood and the healthy development of industries.

The Internet technology mainly includes: technology, big data cloud computing technology, sensor technology, communication technology, storage technology, networking technology, Internet technology, mobile terminal and PC terminal to form the TV terminal and the iPad terminal, radio terminal, electronic media end multiport interaction. The Internet technology across time and space links people life, government affairs, city community, industry, cross-border, integration and innovation, online and offline to link, link is the basic form of the Internet presence. On the Internet platform brings together text, pictures, video information, using the Internet technology analysis for government, industry, business or personal collection, indexing, integration, and storage of data needed to provide a complete, efficient and high value of the data analysis report for the decision, make its behavior more quickly and more accurate, more wisdom.

Internet banking is the traditional financial model to inclusive financial evolution, main form of chips, P2P net loan, the third party payment, digital currency, financial data, financial institutions, financial portal, has the advantages of high efficiency, weak management, high risk, low cost, wide coverage, fast development. Internet banking not only fills the gap of traditional financial market, but also brings huge increment for the financial industry. At the same time, it can improve the national financial competitiveness while reducing the cost of financial services and improving the financial infrastructure. In October 8, 2015 the people's Bank of Chinese opened RMB cross-border payment system, support cross-border direct investment, cross-border trade in goods and services trade settlement, cross-border personal remittances and cross-border financing business, which indicates that China has its own independent settlement way in the financial field of the world, marking the domestic and international payment of RMB payment integrated modern payment system construction has made important progress.

\section{Conclusion}

To carry out entrepreneurship education in colleges and universities, to improve the students' entrepreneurial ability, is the main way to solve the employment problem of college students, are also effective measures to alleviate the employment pressure, and realize the popularization of higher education is the inevitable choice, more adapt to the development of personnel training requirements of the socialist market economy. In the transformation from entrepreneurship education to entrepreneurial practice, government departments need to further create a fair market environment for entrepreneurs and provide preferential policies. As far as colleges and universities are concerned, improving the curriculum system of entrepreneurship education, improving the quality of entrepreneurial instructors and enhancing the feasibility of entrepreneurial projects are all the problems that should be paid attention to in the future of entrepreneurship education in colleges and universities.

\section{References}

[1]. Kyrö, Paula. "The conceptual contribution of education to research on entrepreneurship education." Entrepreneurship \& Regional Development 27.9-10 (2015): 599-618.

[2]. O'Connor, Allan. "A conceptual framework for entrepreneurship education policy: Meeting government and economic purposes." Journal of Business Venturing 28.4 (2013): 546-563.

[3]. Schindehutte, Minet, and Michael H. Morris. "8. The experiential learning portfolio and entrepreneurship education." Annals of Entrepreneurship Education and Pedagogy-2016 (2016).

[4]. Wang, H. and Wang, J., 2014, November. An effective image representation method using kernel classification. In Tools with Artificial Intelligence (ICTAI), 2014 IEEE 26th International Conference on (pp. 853-858). IEEE. 